\title{
SOIL CONDITIONER EFFECT \\ ON SOIL WETTING PATTERNS UNDER PULSED DRIP IRRIGATION SYSTEM
}

\author{
Abd-elhakim, A. Ibrahim*
}

\begin{abstract}
Optimal drip irrigation design and management depend on soil wetting patterns where, sandy soil under continuous drip irrigation was the depth of wetting pattern is relatively higher than the width that leads to increase deep percolation beyond root zone. Therefore, the study aim to improve drip irrigation efficiency using soil conditioners with pulse drip irrigation. An empirical mathematical model was used to describe soil wetting patterns. The laboratory experiments were conducted on sand soil using soil conditioners named commercially by Composite that contains mixed materials in the rate of 5:1 from local "Aswan Clay and Hydrogel (super absorption polymer, SAP) with pulsed drip irrigation at cycle ratio equal 0.5 for different cycles times " $P$ " (20, 30, 40 and 60 minutes). And also, an empirical model by Al-Ogaidi, et al., (2016) was used to estimate the wetted radius of dripper at the soil surface and at the depth of the wetting pattern. Results demonstrated that using composite with pulse flow technique in sand soil led to increase both soil moisture distribution, moisture percent, and the wetting front advances in horizontal direction more than vertical direction. Percentage of the surface and maximum wetted radius to wetted depth under dripper were increased. Also, the percentage of the soil surface wetted radius for all treatments compared to continuous flow without soil conditioner was increased. Predicted and observed values were compared well to test model applicability in laboratory conditions on the basis of model performance parameters. The result shows the advantage of soil conditioner with pulsed flow method for reducing the deep percolation of water under the root zone, while obtaining a wide horizontal spread of wetting.
\end{abstract}

* Researcher, Agricultural Engineering Research Institute (AENRI) El-Dokki, ARC Giza. 


\section{INTRODUCTION}

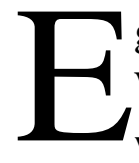
gypt has been suffering from severe water scarcity in recent years. When using drip irrigation, the infiltrated water in the soil forms a wetted zone of a shape similar to a truncated sphere or ellipsoid depending on the total volume of applied water, emitter discharge, and soil hydraulic properties. From optimum techniques to improve soil wetting patterns in sandy soil was pulsed drip irrigation with soil conditioners to increase irrigation efficiency whereas, Pulsing irrigation refer to the practice of irrigating for a short period then waiting for another short period, and repeating this on-off cycle until the entire irrigation water is applied. (Eric et al., 2004). Pulse drip irrigation is used in a lot of arid and semi-arid regions, largely to reduce water losses and to improve crop yields and water use efficiency. Applying pulse drip irrigation technique lead to increase in water movement in horizontal direction more than vertical direction thus increasing in water soil volume (Li, et al., 2004; Bakeer, et al., 2009; Skaggset et al.,2010; Abdel tawab, 2015). Ismail, et al., (2014) reported that the advantage of pulse flow, for reducing the deep percolation of water under the crop root zone, while obtaining a wide horizontal spread of wetting. This enables using a highly discharge emitter with the same amount of water.

Soil conditioners positively affect hydro-physical properties of sandy soil, decreasing soil bulk density as well as macro porosity (drainage pores) on the expense of micro ones therefore, water-holding pores were increased ), their ability to increase soil moisture for longer periods, improve seed emergence, reduce crust problems and also, increase Horizontal wetting front advance, while led to reduce infiltration, saturated hydraulic conductivity and deep percolation losses (Al-Darby, 1996; El-Hady, et al., 2006; Maghchiche et al., 2010; Ali ,2011; and Zin El-Abedin, et al., 2015). Hydrogel as soil conditioner is the commercial name for super absorbent polymer (SAP) where, the use of super absorbent polymers (hydrogels) for soil conditioning is considered an effective way to solve the problems of water limitation of sandy soils for reclamation of newly desert areas. Yanget al., (2014) indicated that SAP with good water retention properties, was very effective in enhancing water uptake and utilization of water for plants growth. 
The wetting patterns are one of an important factor to consider when designing and managing a drip irrigation system (Dasberg and Or, 1999). Several models have been developed to determine the wetting pattern under drip irrigation systems. The most common models are numerical, analytical, and empirical models (Subbaiah, 2013), to estimate only the wetted radius at the soil surface and the wetted depth at the surface or subsurface drip irrigation system. Al-Ogaidi et al., (2016) developed an empirical model to estimate the vertical and horizontal advance of the wetting front at different application times whereas, the proposed model predicts the full wetting pattern with acceptable accuracy and performs well in replicating published experimental data.

The use of soil conditioners as 'composite' material is considered as an effective way to solve the problems of water limitation of sandy soils for reclamation of newly desert areas whereas lead to increase in water movement in vertical direction more than horizontal direction under continuous drip irrigation. Therefore, the objective of this research was to study the effect of the use of soil conditioners on sandy soil wetting patterns under pulsed drip irrigation system, and use an empirical model by (Al-Ogaidi, et al., 2016) to describe the full wetting pattern.

\section{MATERIAL AND METHODS}

\section{Laboratory experiment}

The laboratory experiments were conducted at pumps test Laboratory, Testing and Research Station for Tractors and Farm Machinery, Alexandria Governorate. A soil container of internal dimensions $(50 \mathrm{~cm}$ length, $50 \mathrm{~cm}$ width, and $60 \mathrm{~cm}$ depth) was used in the experiments as shown in Fig.(1). The glass container was used; two sides of this container are draw coordinates around dripper to monitor the advance of wetting patterns at different times during the experiments. Soil type that used in the experiments was a sandy soil. Enough soils' amounts were collected, spread; air dried, sieved through a $2 \mathrm{~mm}$ screen, mixed thoroughly to achieve constant water content, and packed in plastic bags to maintain approximately the same water content for the whole soil. The soil properties are listed in Table 1. The used soil conditioners named commercially Composite that consists of mixed materials in the rate of 5:1 from local "Aswan Clay and Hydrogel (super absorption polymer, 
SAP) as shown in Fig.(2). This material was placed and covered it in a sandy soil at depth of $10 \mathrm{~cm}$ from soil surface. From advantages this material its ability to absorption of water, and storage it then it's give for plants roots effectively.

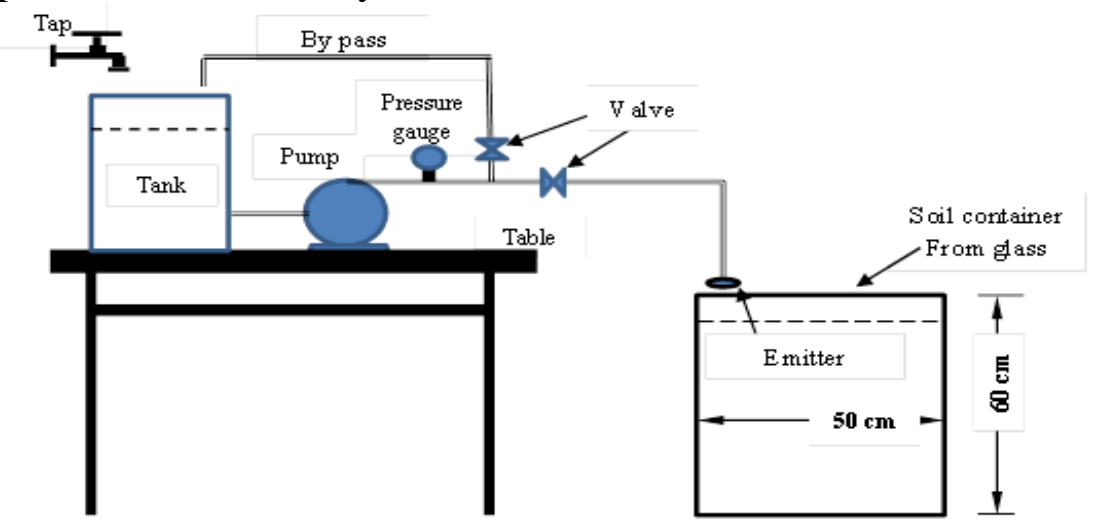

Fig. (1): Schematic view of the soil container and water application system.

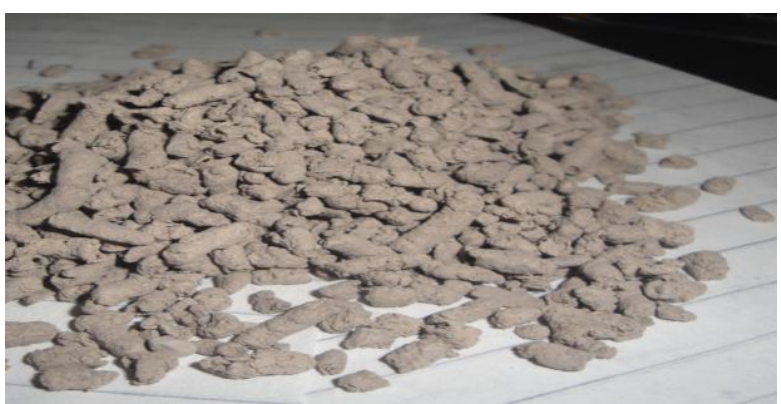

Fig. (2): Schematic view of Soil conditioner materials "composite".

Water supplying system contains water tank, pump which give the required hydraulic head, bypass line into water tank and valve to control and adjust the hydraulic head at 0.5 bar, pressure gauge, and line into soil container that finished with dripper. Average dripper discharge was $2 \mathrm{l} / \mathrm{hr}$ whereas, it was calibrated before carrying out the experiment. This container represents one of four parts of the complete cylinder i.e. quarter of the wetted zone was considered in the experiments so the actual emitter discharges were multiplied by 4 . Experimental variables were water application time (continuous "C" or pulse) and composite. Pulsed water application times were at cycle ratio equal 0.5 for different cycles times "P" (20, 30, 40 and 60 minutes). The locations of the wetting patterns 
were recorded by determined points of coordinates on transparent side of the container around dripper at specified times during the experiments. As well as, width and depth of wetting were measured. Soil samples were taking to investigate water content distribution in the soil by auger from the soil profile after irrigation directly on distances of $10 \mathrm{~cm}$ in horizontal and vertical direction from the emitter until $50 \mathrm{~cm}$ for the maximum container horizontal and vertical limit. Soil moisture content was determined by the gravimetric methods and represented using "contouring program Surfer" we obtained on contouring maps for different moisture levels. The wetting patterns were recorded by determined points of coordinates at end of on time and start at off time in pulsed drip irrigation.

\section{Empirical model Description}

When using surface drip irrigation, the infiltrated water in the soil forms a wetted zone of a shape similar to a truncated sphere or ellipsoid depending on factors are associated with soil characteristics which are; initial moisture content, saturated hydraulic conductivity, bulk density and the homogeneity of the soil. While the other part of these factors are related to the properties of the drip irrigation system such as emitter's discharge and location (surface or subsurface), water application method (continuous or pulse) and spacing between emitters and laterals. An empirical model developed by Al-Ogaidi, et al., (2016) was used to estimate the wetted zones' dimensions with add porosity factor for the model under pulsed drip irrigation compared to continuous drip irrigation with using soil conditioners as composite materials and including the effect of emitter's discharge, application time, bulk density, initial moisture content, saturated hydraulic conductivity, porosity, and the percentages of sand, silt ، and clay of the soil. The general form of the used model for homogeneous profiles assumed to be as in Eqs. (1) and (2) as the following.

$$
\begin{aligned}
& R_{0}=a t^{a 1} q^{a 2} \rho_{b}{ }^{a 3} \theta_{i}^{a 4} K_{s}{ }^{a 5} \emptyset^{a 6} S^{a 7} S i^{a 8} C^{a 9} \\
& D=b t^{b 1} q^{b 2} \rho_{b}{ }^{b 3} \theta_{i}^{b 4} K_{s}^{b 5} \emptyset^{b 6} S^{b 7} S i^{b 8} C^{b 9}
\end{aligned}
$$

Where Ro $(\mathrm{cm})$ and D $(\mathrm{cm})$ are the on soil surface radius and depth of the wetted zone, respectively, $\mathrm{t}(\mathrm{min})$ is the application time, $\mathrm{q}(\mathrm{l} / \mathrm{h})$ is the 
emitter's discharge, $\rho b$ is $\left(\mathrm{g} / \mathrm{cm}^{3}\right)$ is the soil bulk density, $\Theta i(\%)$ is the average initial water content, $\mathrm{Ks}(\mathrm{cm} / \mathrm{hr})$ is the saturated hydraulic conductivity, $\varnothing$ is porosity percent, $\mathrm{S}, \mathrm{Si}$, and $\mathrm{C}(\%)$ are the percent-ages of the sand, silt, and clay, respectively, and a to a9 and b to b9 are empirical coefficients.

The above used models are for predicting only two dimensions of the wetting pattern: the on soil surface radius and the depth, for a certain application time. The wetted radius at multiple depths under the soil surface was estimated using a model similar to Eq. 1 for homogeneous but just by adding another coefficient to each equation as demonstrated in the empirical Eq. (3) for homogeneous profile.

$$
R_{z}=c t^{c_{1}} q^{c_{2}} \rho_{b}{ }^{c_{s}} \theta_{i}^{c_{4}} K_{s}^{c_{5}} \emptyset^{c_{6}} S^{c_{7}} S i^{c_{8}} C^{c_{9}}+c_{10}
$$

Where $\mathrm{Rz}(\mathrm{cm})$ is the maximum wetted radius beneath the soil surface at depth $\mathrm{z}(\mathrm{cm}), \mathrm{c}$ to $\mathrm{c} 10$ are empirical coefficients. The influence of all these factors should be taken into consideration because all of them contribute to form the shape of the wetting pattern.

\section{Model Performance}

The predicted wetting pattern dimensions were obtained where, using the data obtained from the laboratory experiments and conducting the nonlinear regression analysis using Microsoft Excel Solver tool 2013. The performance of each model was represented by considering some statistical criteria such as mean error ME, root mean square error RMSE, and model efficiency EF which can be calculated as illustrated in follows Eqs. $4-6$ (Willmot et al., 2012):

$$
\begin{aligned}
& M E=\frac{1}{N}\left|\sum_{i=1}^{N}\left(P_{i}-O_{i}\right)\right| \\
& R M S E=\left[\frac{1}{N} \sum_{i=1}^{N}\left(P_{i}-O_{i}\right)^{2}\right]^{0.5} \\
& E F=1-\frac{\sum_{j=1}^{N}\left(P_{i}-o_{i}\right)^{2}}{\sum_{i=1}^{N}\left(o_{i}-o_{a v}\right)^{2}}
\end{aligned}
$$

Where $\mathrm{N}$ : is the total number of points, $\mathrm{P}$ and $\mathrm{O}$ are referred to predicted and observed data, respectively, and Oav is the mean value of the observed data. The coefficients of Eqs. (1)-(3) were concluded under 
experimental conditions with calculated some statistical criteria and listed in Table 2.

Table 1: The used soil's properties.

\begin{tabular}{|l|l|l|l|l|l|l|l|}
\hline Soil & Sand $\%$ & Silt $\%$ & Clay\% & $\Theta i \%$ & $\rho b\left(\mathrm{~g} / \mathrm{cm}^{3}\right)$ & $\mathrm{Ks}(\mathrm{cm} / \mathrm{hr})$ & $\varnothing, \%$ \\
\hline Sand & 94.5 & 3.62 & 1.88 & 4.95 & 1.65 & 24.75 & 38 \\
\hline
\end{tabular}

Table 2: The coefficients of the proposed models with statistical criteria.

\begin{tabular}{|c|c|c|c|c|c|c|c|c|c|c|c|c|c|c|c|}
\hline \multicolumn{2}{|c|}{ Equation (1) } & $\mathrm{a}$ & a1 & a2 & a3 & a4 & a5 & a6 & a7 & a8 & a9 & & ME & RMSE & $\mathrm{EF}$ \\
\hline \multirow{6}{*}{$\begin{array}{l}\text { Without } \\
\text { Composite }\end{array}$} & Continuous & 0.55 & 0.19 & -0.42 & -0.62 & 4.39 & -4.52 & 1.23 & 0.04 & 5.87 & -12.95 & & 0.38 & 0.52 & 0.99 \\
\hline & P20 & 0.69 & 0.28 & -0.26 & 0.42 & -3.76 & -2.80 & 0.76 & 0.03 & 6.90 & -5.84 & & 0.80 & 1.06 & 0.97 \\
\hline & P30 & 1.15 & 0.21 & 0.03 & 2.67 & 10.50 & -10.49 & -0.04 & 0.00 & -0.13 & -16.42 & & 1.20 & 1.33 & 0.96 \\
\hline & $\mathrm{P} 40$ & 0.31 & 0.21 & -0.89 & -1.30 & 9.10 & -9.36 & 2.55 & 0.07 & 1.63 & -17.54 & & 1.11 & 1.46 & 0.96 \\
\hline & $\mathrm{P} 60$ & 1.12 & 0.33 & 0.08 & 0.06 & 0.00 & 0.35 & 0.00 & 0.00 & 0.00 & 0.00 & & 0.75 & 1.16 & 0.98 \\
\hline & Continuous & 1.28 & 0.21 & 0.03 & 0.02 & -0.13 & 0.14 & -0.04 & 0.00 & -0.15 & -0.17 & & 2.24 & 2.62 & 0.89 \\
\hline \multirow{4}{*}{$\begin{array}{l}\text { With } \\
\text { Composite }\end{array}$} & P20 & 1.05 & 0.37 & 0.03 & 0.02 & -0.14 & 0.15 & -0.05 & 0.00 & -0.16 & -0.04 & & 1.41 & 2.02 & 0.97 \\
\hline & $\mathrm{P} 30$ & 0.55 & 0.27 & -0.42 & -0.62 & 4.38 & -4.50 & 1.23 & 0.03 & 5.86 & -13.03 & & 0.94 & 1.45 & 0.99 \\
\hline & $\mathrm{P} 40$ & 1.10 & 0.24 & 0.03 & 0.02 & -0.14 & 0.15 & -0.05 & 0.00 & -0.16 & -0.19 & & 0.47 & 1.60 & 0.98 \\
\hline & $\mathrm{P} 60$ & 0.28 & 0.37 & -0.89 & -1.30 & 9.12 & -9.38 & 2.56 & 0.07 & 1.65 & -17.51 & & 1.16 & 1.74 & 0.98 \\
\hline \multicolumn{2}{|c|}{ Equation (2) } & b & b1 & b2 & b3 & $\mathrm{b} 4$ & b5 & b6 & b7 & b8 & b9 & & & & \\
\hline \multirow{5}{*}{$\begin{array}{l}\text { Without } \\
\text { Composite }\end{array}$} & Continuous & 1.04 & 0.54 & 0.03 & 0.02 & -0.13 & 0.14 & -0.04 & 0.00 & -0.14 & -0.01 & & 1.73 & 2.22 & 0.98 \\
\hline & P20 & 1.22 & 0.45 & 0.07 & 0.05 & 0.00 & 0.33 & 0.00 & 0.00 & 0.00 & 0.00 & & 0.78 & 2.08 & 0.97 \\
\hline & $\mathrm{P} 30$ & 7.55 & 0.53 & 2.00 & 0.00 & 0.35 & 34.90 & 0.13 & 120.00 & 7.23 & 20.76 & & 0.22 & 2.29 & 0.97 \\
\hline & P40 & 5.39 & 0.40 & 1.06 & 0.20 & 0.28 & 0.00 & 0.00 & 0.00 & 0.00 & 0.00 & & 0.41 & 0.97 & 0.996 \\
\hline & P60 & 1.43 & 0.29 & 0.12 & 0.09 & 0.00 & 0.55 & 0.00 & 0.00 & 0.00 & 0.00 & & 1.11 & 1.60 & 0.99 \\
\hline \multirow{5}{*}{$\begin{array}{l}\text { With } \\
\text { Composite }\end{array}$} & Continuous & 0.77 & 0.30 & -0.25 & 0.42 & -3.76 & -2.80 & 0.76 & 0.01 & 6.89 & -5.87 & & 0.76 & 1.23 & 0.98 \\
\hline & P20 & 1.04 & 0.40 & 0.03 & 0.02 & -0.13 & 0.14 & -0.04 & 0.00 & -0.14 & 0.03 & & 2.43 & 2.89 & 0.91 \\
\hline & P30 & 1.02 & 0.40 & 0.01 & 0.01 & -0.06 & 0.06 & -0.02 & 0.00 & -0.06 & -0.08 & & 1.90 & 2.77 & 0.87 \\
\hline & P40 & 1.03 & 0.32 & 0.02 & 0.02 & -0.09 & 0.10 & -0.03 & 0.00 & -0.10 & -0.12 & & 0.96 & 1.78 & 0.95 \\
\hline & $\mathrm{P} 60$ & 0.28 & 0.23 & -0.89 & -1.30 & 9.11 & -9.37 & 2.56 & 0.07 & 1.63 & -17.59 & & 0.68 & 1.18 & 0.98 \\
\hline \multicolumn{2}{|c|}{ Equation (3) } & c & c1 & c2 & c3 & $c 4$ & c5 & c6 & c7 & c8 & c9 & c10 & & & \\
\hline \multirow{5}{*}{$\begin{array}{l}\text { Without } \\
\text { Composite }\end{array}$} & Continuous & 1.03 & 0.89 & 0.02 & 0.01 & -0.08 & 0.08 & -0.03 & 0.00 & -0.09 & 0.49 & 1.03 & 2.49 & 3.27 & 0.76 \\
\hline & P20 & 0.99 & 0.71 & -0.01 & -0.01 & 0.04 & -0.04 & 0.01 & 0.00 & 0.04 & 0.05 & 0.99 & 1.77 & 2.54 & 0.91 \\
\hline & $\mathrm{P} 30$ & 1.03 & 0.54 & 0.02 & 0.02 & -0.09 & 0.10 & -0.03 & 0.00 & -0.10 & 0.14 & 1.03 & 1.62 & 2.10 & 0.96 \\
\hline & P40 & 0.28 & 0.43 & -0.89 & -1.30 & 9.14 & -9.40 & 2.56 & 0.06 & 1.65 & -17.73 & 0.28 & 1.94 & 2.46 & 0.94 \\
\hline & $\mathrm{P} 60$ & 0.94 & 1.18 & -0.04 & -0.03 & 0.19 & -0.20 & 0.06 & 0.00 & 0.21 & 0.25 & 0.94 & 0.82 & 2.64 & 0.96 \\
\hline \multirow{5}{*}{$\begin{array}{l}\text { With } \\
\text { Composite }\end{array}$} & Continuous & 1.03 & 1.07 & 0.02 & 0.01 & -0.09 & -2.08 & $\begin{array}{c}-0.03 \\
\end{array}$ & 0.00 & -0.10 & -1.08 & 0.34 & 3.18 & 4.56 & 0.92 \\
\hline & P20 & 1.00 & 0.44 & 0.00 & 0.00 & 0.83 & 2.19 & 0.70 & 0.02 & 0.75 & 0.00 & 1.00 & 1.79 & 3.21 & 0.94 \\
\hline & $\mathrm{P} 30$ & 0.55 & 0.26 & -0.42 & -0.62 & 4.38 & -4.50 & 1.22 & 0.03 & 5.85 & -13.09 & 0.55 & 2.74 & 3.50 & 0.95 \\
\hline & P40 & 1.64 & 0.26 & 0.13 & 0.02 & -0.13 & 0.14 & -0.04 & 0.00 & -0.14 & -0.12 & 1.04 & 2.74 & 4.41 & 0.92 \\
\hline & $\mathrm{P} 60$ & 0.07 & 0.75 & -0.92 & -1.32 & 9.26 & -9.53 & 2.60 & 0.07 & 1.78 & -17.76 & 0.26 & 3.35 & 5.04 & 0.91 \\
\hline
\end{tabular}

\section{RESULTS AND DISCUSSIONS}

\section{Moisture content distribution}

Soil moisture distribution "MCD" was the main factor in study of effect use of composite and the evaluation process for pulse drip irrigation performance. Results demonstrated that MCD increased in horizontal direction more than vertical direction under use of Composite with pulsed drip irrigation for treatments (P30, P40, and P60) effectively more than treatments (P20 and C) in Fig.(3). 
a
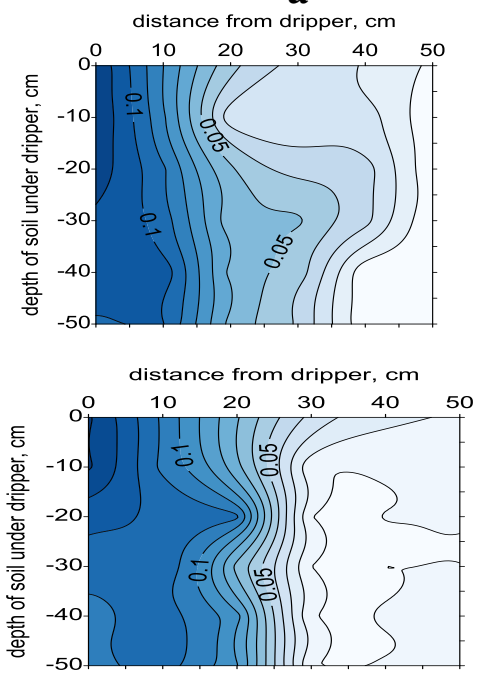

distance from dripper, $\mathrm{cm}$

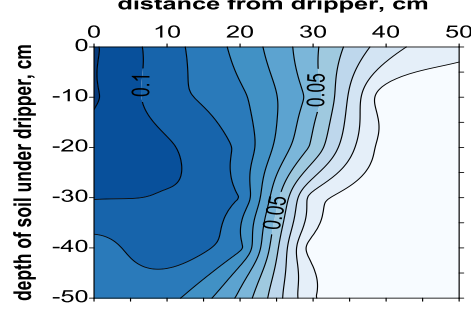

distance from dripper, $\mathrm{cm}$
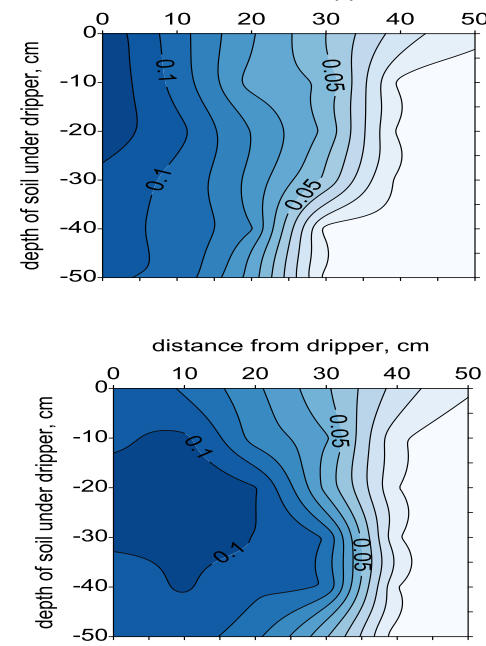

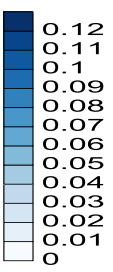

C

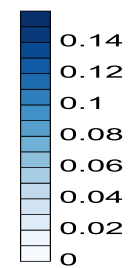

\section{P20}
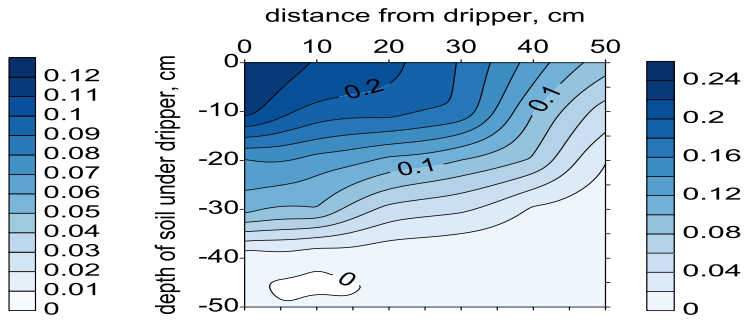

\section{P30}
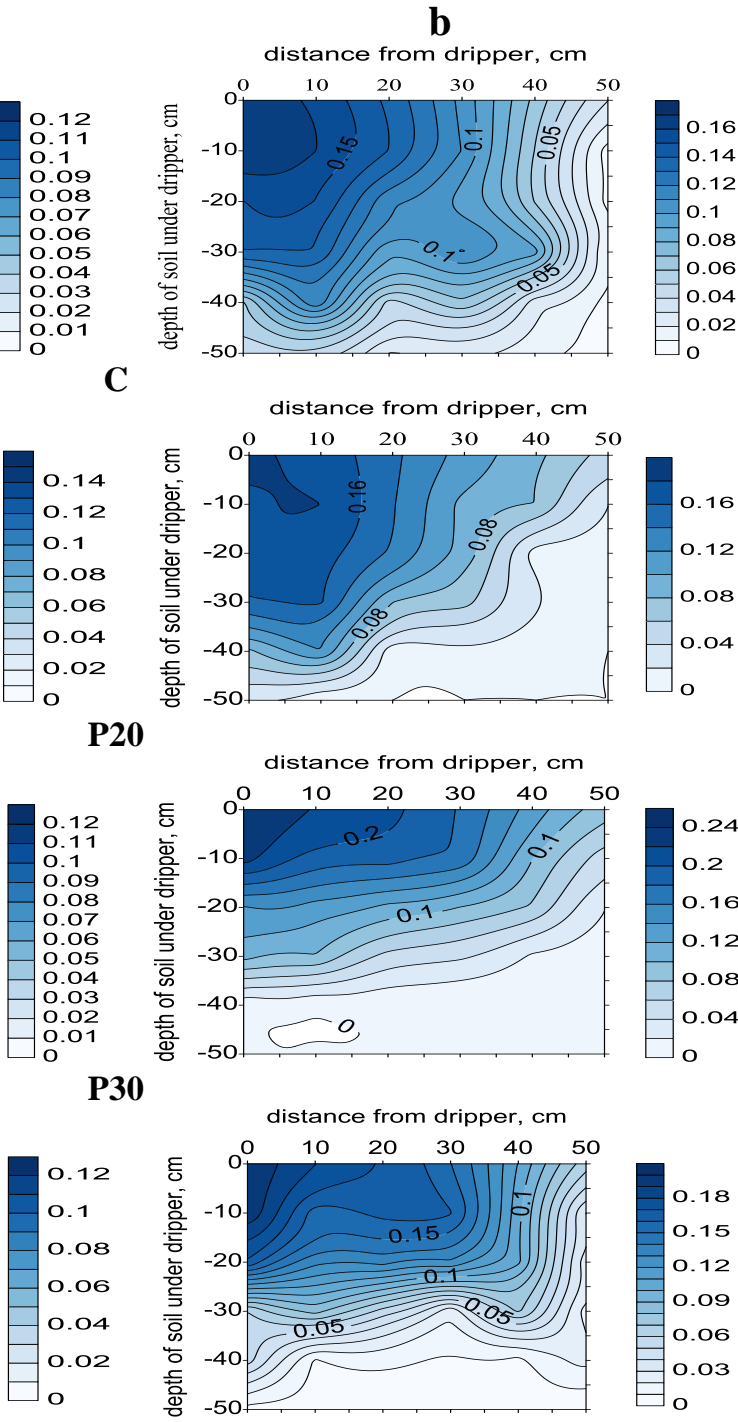

P40
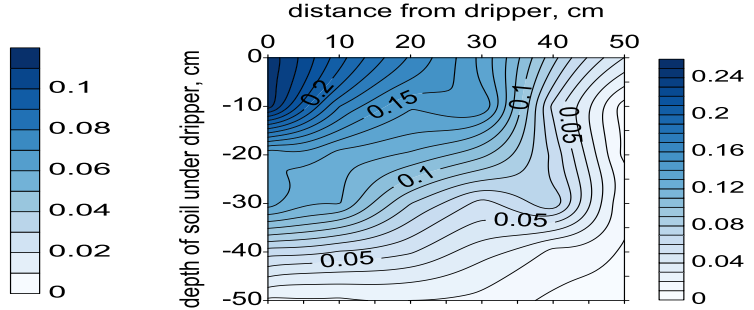

P60

Fig. (3): The measured water content distribution at the end of experiment: a) without and, b)with using composite under continuous " $\mathrm{C}$ " and pulsed drip irrigation for different cycles times "P" 
All pulsed flow treatments with composite much better than pulsed technique treatments only. On the contrary, MCD increased in vertical direction more than horizontal direction under continuous flow without composite. Whereas, MCD increased by increasing number of pulses for pulse technique with composite. This leads to save water from deep percolation. In addition to, this material have ability to absorption of water, and storage it then it's give for plants roots effectively. Also, it found that soil moisture content percentages increased which were (24, 21, 24, 18, and $16 \%$ ) for Treatments (P60, P40, P30; and C) with use composite respectively, because of increase holding capacity for polymer and its ability to absorption of water, and storage its that was calculated 14 times from its weight after the irrigation. While, MCD percentages were in range 12 to $14 \%$ for continuous and pulsed irrigation technique treatments without use composite.

\section{Wetted radius and depth under soil conditioner}

The information on depths and radius of wetted zone of soil plays the greatest role in design and management of drip irrigation system. The results showed that the wetted radius $\left(\mathrm{R}_{0}\right)$ of dripper at soil surface increased more than wetted depth (D) under dripper at use of composite with pulse flow large greatly as showed in Fig. (4) Which, It takes total on-time $(270,120,135,140$ and $150 \mathrm{~min})$ for treatments (C, P20, P30, $\mathrm{P} 40$, and P60), respectively. While, in case of pulsed irrigation only without composite, the wetted radius increased slightly but the wetted radius less than wetted depth. This result is in agreement with (Ismail, et al., 2014).

Also, percent of the wetted radius at soil surface to wetted depth under dripper $\left(\mathrm{R}_{0} / \mathrm{D}\right)$ were $(0.97,1.26,1.62,1.59$, and 1.48$)$ with composite while, $\left(\mathrm{R}_{0} / \mathrm{D}\right)$ were $(0.32,0.46,0.48,0.50$ and 0.52$)$ without composite for treatments (C, P20, P30, P40, and P60), respectively. Otherwise, the percentage of increase in wetted radius at the soil surface (Ri) compared to wetted radius for continuous without composite (control, $\mathrm{Rc}=16 \mathrm{~cm}$ ) was $\left(\Delta \mathrm{R}_{0}=(\mathrm{Ri}-\mathrm{Rc}) / \mathrm{Rc}\right)$. For pulsed irrigation without composite, $\left(\Delta \mathrm{R}_{0}\right)$ was $(0.44,0.50,0.56$, and 0.63$)$ for treatment (P20, P30, P40, and P60) respectively, but at use of composite only, $\left(\Delta \mathrm{R}_{0}\right)$ was 1.06 for continuous. 
For pulse irrigation method with composite, $\left(\Delta \mathrm{R}_{0}\right)$ was $(1.75,1.94,1.69$ and 1.50) for treatments (P20, P30, P40, and P60), respectively.

a
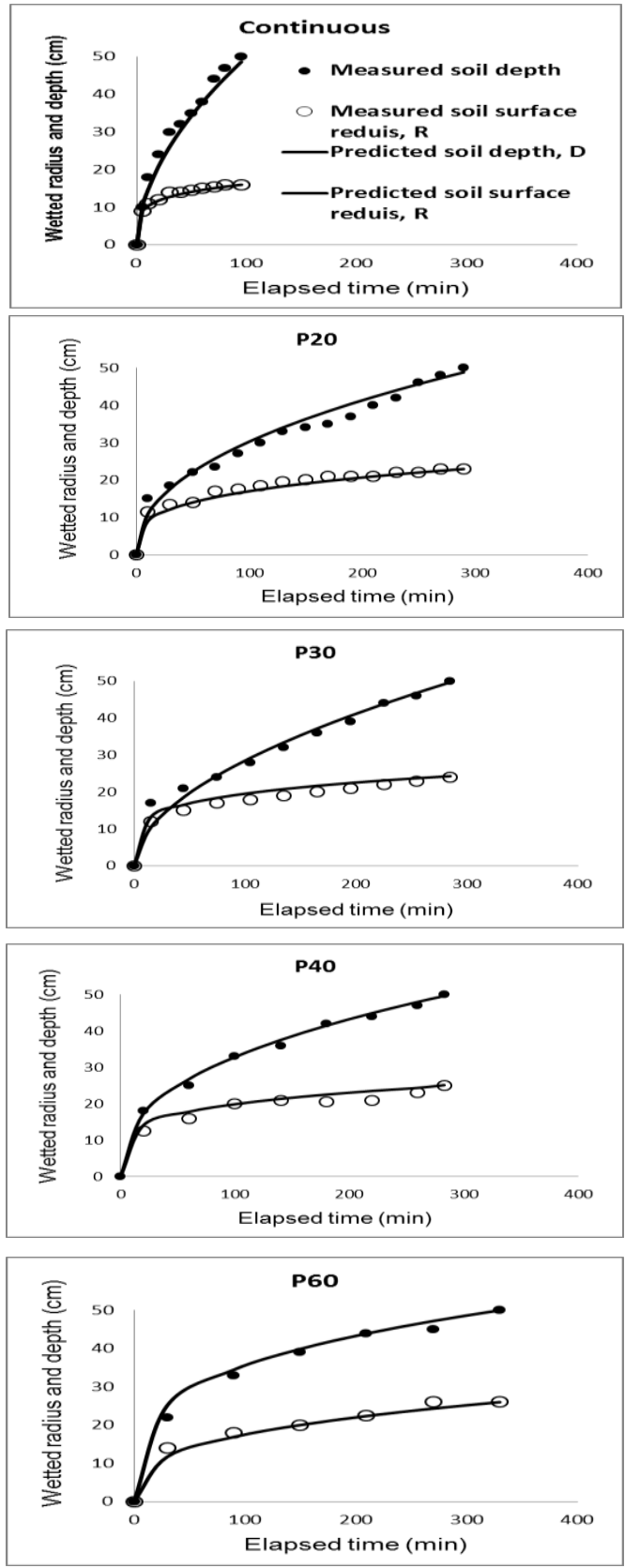

b
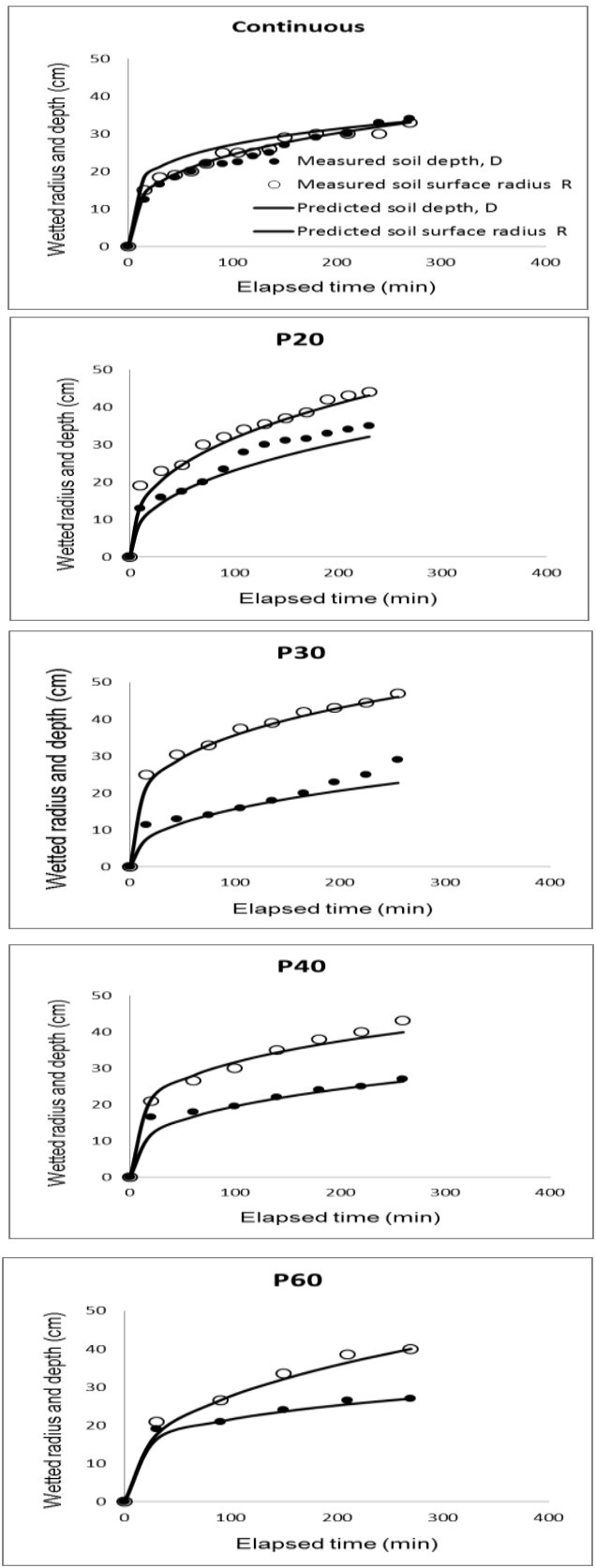

Fig. (4): The wetting pattern dimensions against the application times: a)without and, b) with using composite under continuous and pulsed drip irrigation for different 
Fig. (5) showed the relationship between measured and predicted wetted radius also the relationship between measured and predicted wetted depth for treatments (C, P20, P30, P40, and P60) respectively, without and with composite, The relationship is approximately linear curve; It is clear that there is a good harmony between measured and predicted wetted patterns values.

\section{The maximum wetted radius ( $R \max )$ in soil profile}

The results showed that $\left(R_{\max }\right)$ increased more than wetted depth (D) under dripper with composite and pulse flow as shown in Fig. (6) which, It takes total on-time $(270,120,135,140$ and $150 \mathrm{~min})$ for treatments $(\mathrm{C}$, P20, P30, P40, and P60), respectively. While, in case of pulsed irrigation only without composite, ( $\mathrm{Rmax}$ ) increased and wetted depth decreased. The same result was obtained by (Ismail, et al., 2014) but the maximum wetted radius less than wetted depth. The maximum wetted radius is clear for all the trials greater than the surface wetted radius. (Rmax) happened at a depths below the soil surface were $(25,20,20,15$ and $20 \mathrm{~cm})$ without composite while, $(\mathrm{Rmax})$ were $(15,5,5,10$ and $10 \mathrm{~cm})$ with composite for treatments (C, P20, P30, P40, and P60), respectively. Percent of the maximum wetted radius ( $R \max )$ under soil surface to wetted depth under dripper $(\mathrm{Rmax} / \mathrm{D})$ were $(1.47,1.43,1.72,1.85$, and 1.85) with composite while, $(\mathrm{Rmax} / \mathrm{D})$ were $(0.4,0.6,0.7,0.7$ and 0.8$)$ without composite for treatments (C, P20, P30, P40, and P60) respectively. Otherwise, the percentage of increase in the maximum wetted radius ( $\mathrm{Rmax}$ ) compared to maximum wetted radius for continuous without composite (control, $\mathrm{Rc}=$ $20 \mathrm{~cm})$ was $(\Delta \mathrm{R} \max =(\mathrm{R} \max -\mathrm{Rc}) / \mathrm{Rc})$. For pulsed irrigation without composite, $(\Delta \mathrm{R} \max )$ was $(0.5,0.75,0.75$, and 1$)$ for treatment $(\mathrm{P} 20, \mathrm{P} 30$, $\mathrm{P} 40$, and $\mathrm{P} 60)$ respectively, but at use composite only, $\left(\Delta \mathrm{R}_{\max }\right)$ was 1.5 for continuous. For use pulse drip irrigation with adding composite, $\left(\Delta \mathrm{R}_{\max }\right)$ was (1.5) for all treatments where, $\mathrm{R}_{\max }$ reached $50 \mathrm{~cm}$ in all treatments. Fig. (7) showed the relationship between the measured and predicted maximum wetted radius for treatments (C, P20, P30, P40, and P60) respectively, without and with use of composite, The relationship is approximately linear curve; It is clear that there is a good harmony between measured and predicted wetted patterns values. 
A
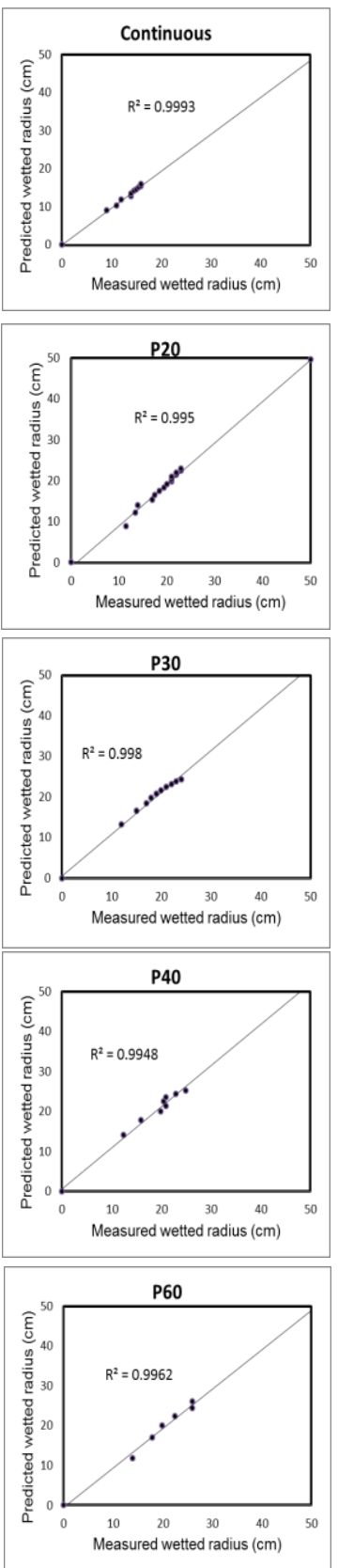

b
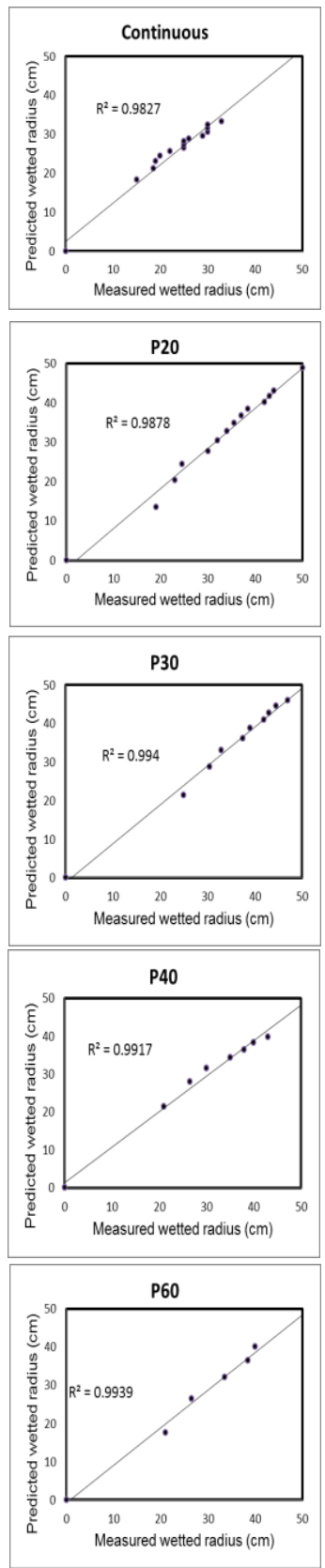

c
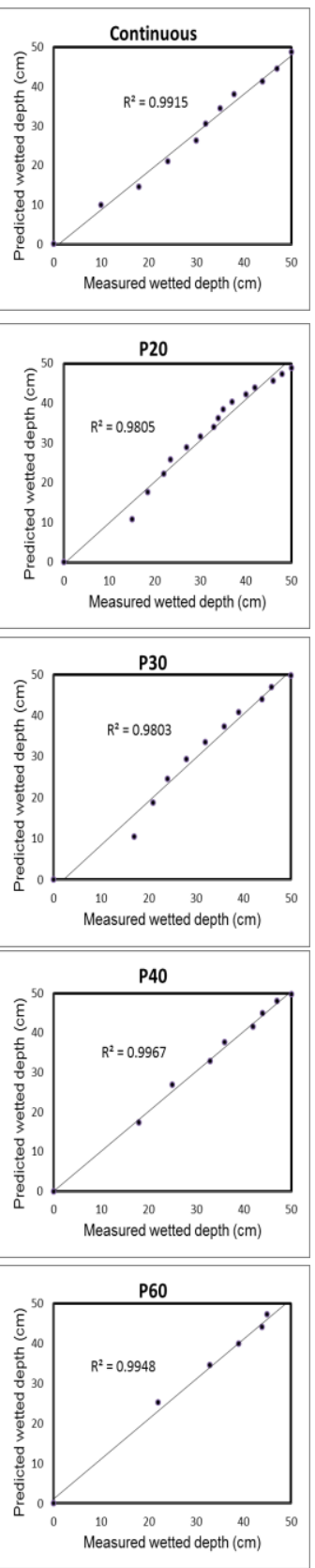

d
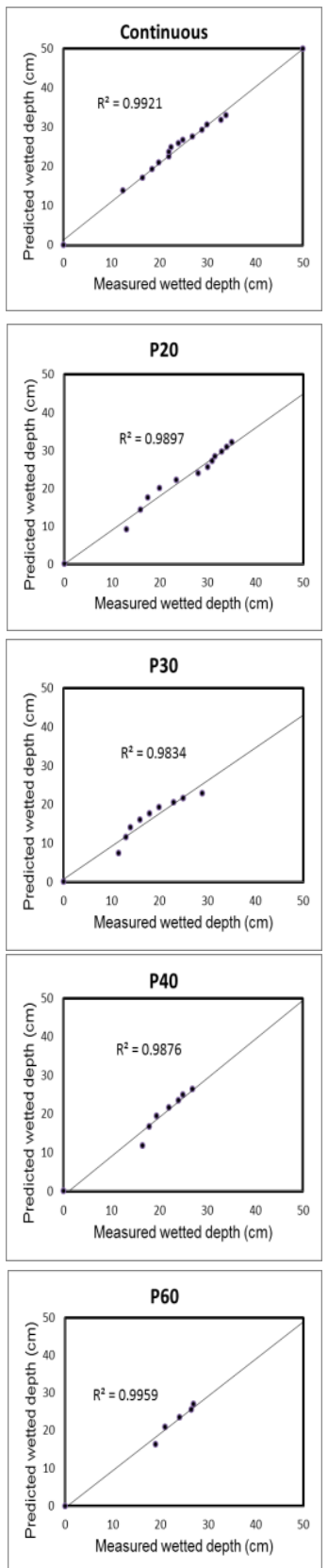

Fig. (5): Predicted and observed wetted dimensions: a) Wetted radius without composite; b) Wetted radius with composite; c) Wetted depth without composite; and d) Wetted depth with composite. 
A
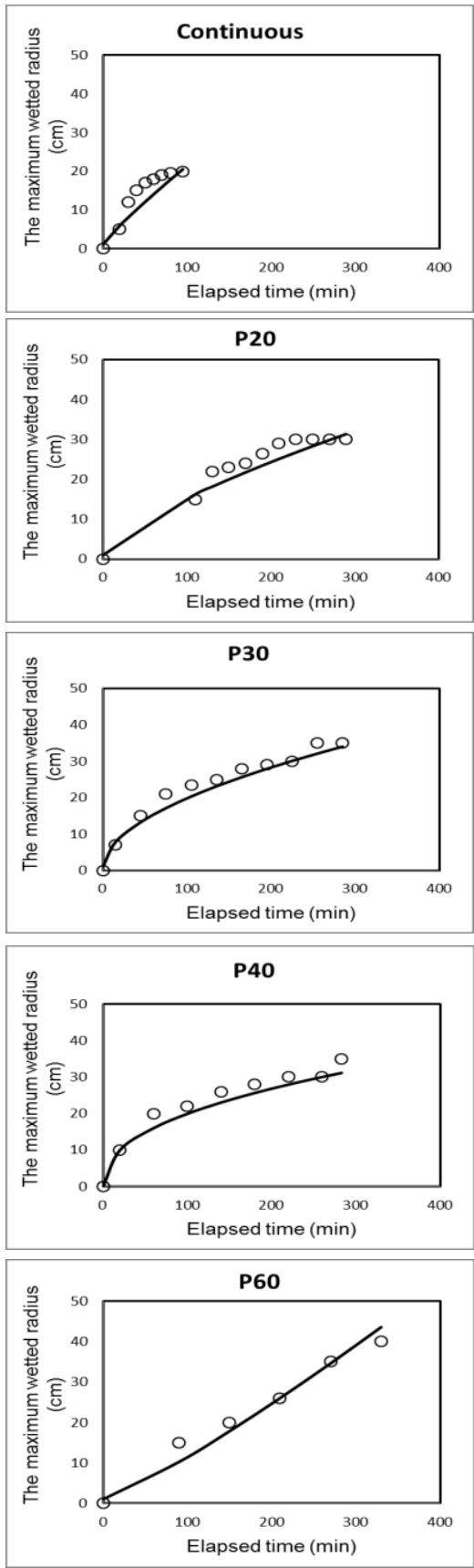

b
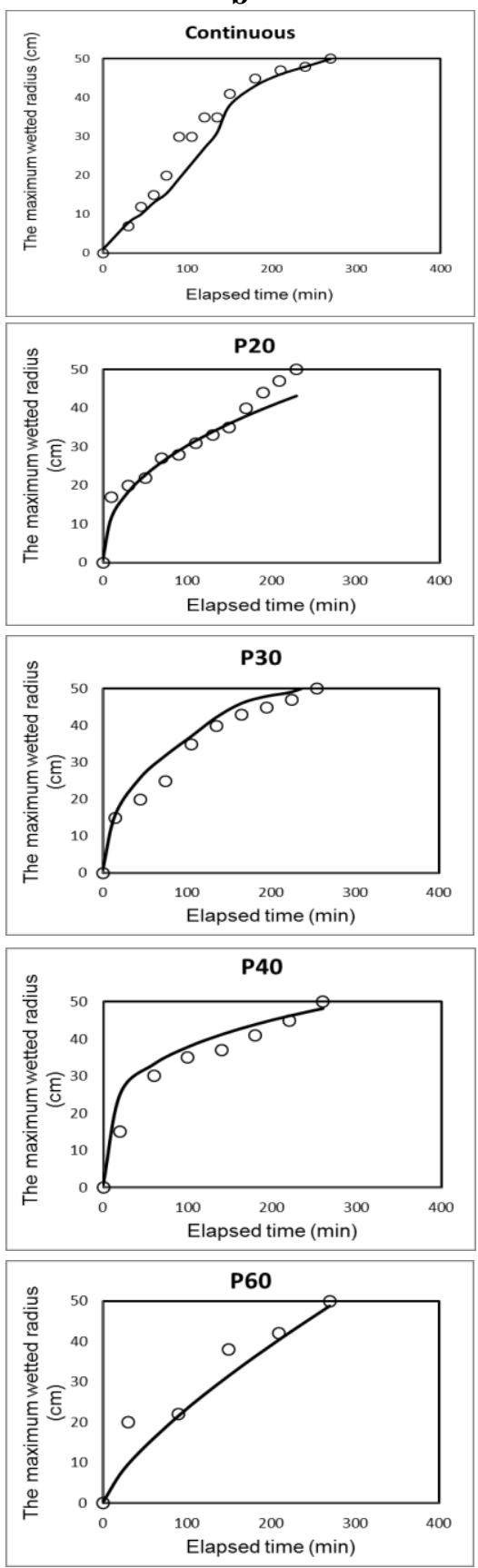

Fig. (6): The maximum wetted radius in soil profile against the application times: a) without and b) with using composite under continuous and pulsed drip irrigation for different cycles times "P". 
$\mathbf{a}$

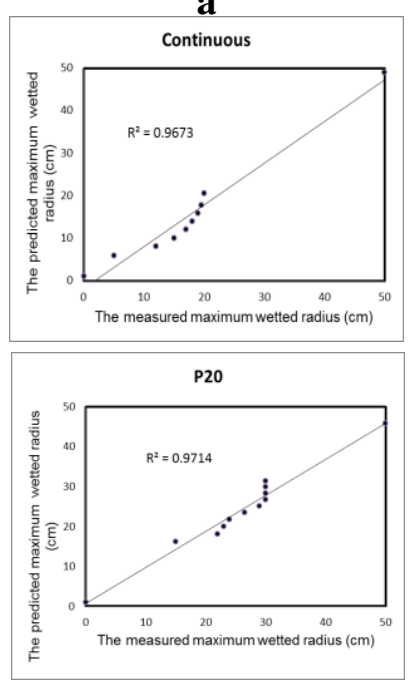

P30

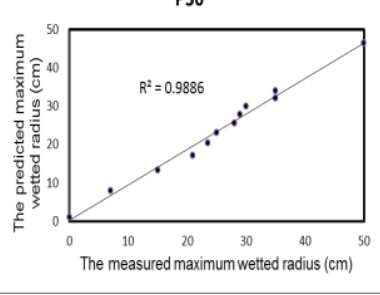

P40

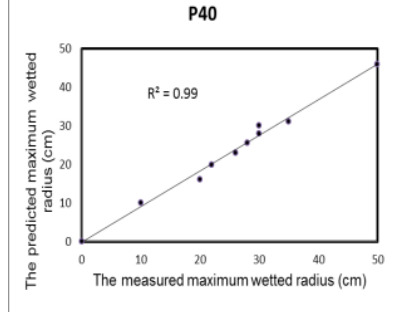

P60

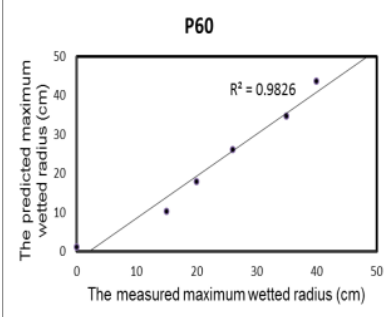

B

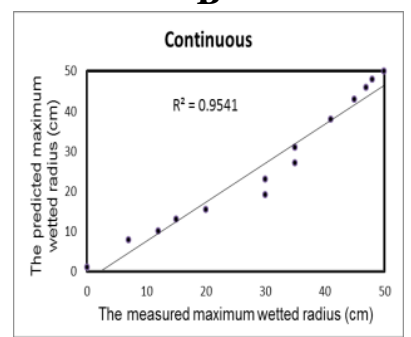

P20

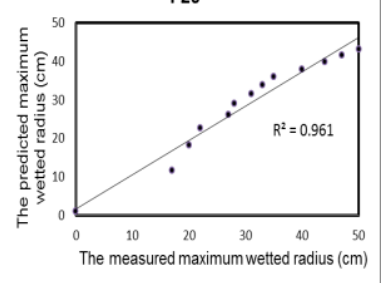

P30
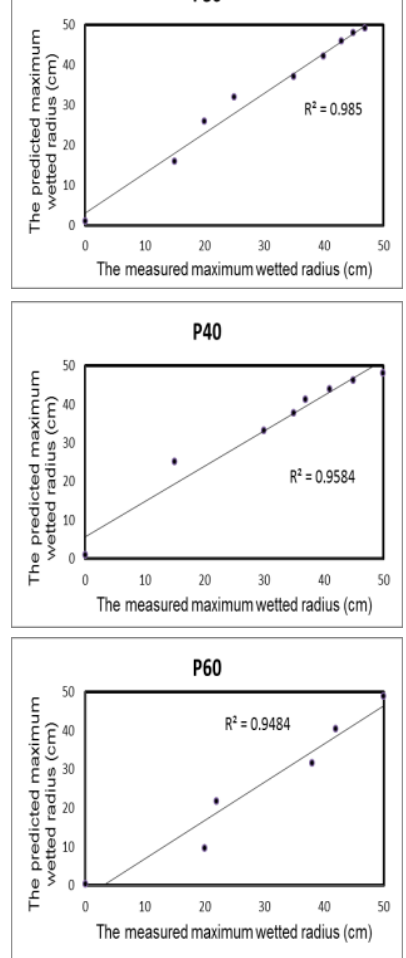

Fig. (7): The predicted and observed maximum wetted radius in soil profile: a) without and, b) with using composite under continuous and pulsed drip irrigation for different cycles times "P". 


\section{Soil wetting front advance}

The wetting pattern will be inferred estimating the wetting pattern because it is very difficult to find a suitable equation to predict the full pattern directly as the shape of this pattern is not uniform. The process of estimating the full shape of wetting pattern begins in predicting the surface wetted radius and vertical wetted depth of a specific application time to get two points of the wedding the wetting pattern. In addition to, the maximum wetted radius in soil profile. The proposed empirical model represented by Eqs.(1) and (2) could be used to get these two points in case of homogeneous soil with $\mathrm{Eq}(3)$ to estimate the full shape of wetting pattern on based on Ellipse shape equation. The dimensions of the wetted zone under drip irrigation are very important in choosing the proper spacing between emitters and laterals. Results showed that an influence composite on the horizontal wetting front advances more than the vertical wetting front advances in continuous flow as shown in Fig. (8) Where, wetting pattern with composite took time about 270 minutes to arrive at vertical limit container longer than no polymer that was about 90 minutes because of composite conditioner save water from deep percolation and its ability to absorption and storage of water largely.

It was noted that there was a influence composite with pulsed irrigation on the horizontal wetting front advances more than the vertical wetting front advances. In case use of pulsed irrigation without composite, there was a good influence on the horizontal wetting front advances more than the vertical wetting front advances but it is less than at use of soil conditioner polymer as shown in Fig. (8). The relationship between measured and predicted Soil wetting front advance values for treatments is clear that there is a good harmony as shown in Fig. (8).

\section{CONCLUSIONS}

Results showed that use composite with pulse flow technique on sand soil compared with pulsed irrigation only led to increase both soil moisture distribution and soil moisture percent in horizontal direction more than vertical direction result to absorption of water, and storage its; Increase of the soil surface wetted radius (R0) more than wetted depth under dripper (D) that demonstrated in increase both percentage of the soil surface wetted radius (R0) to wetted depth also, 
A

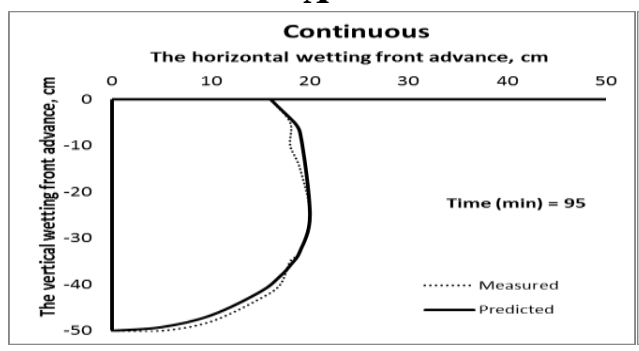

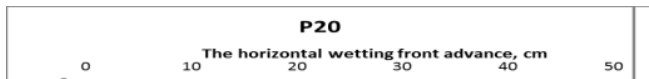
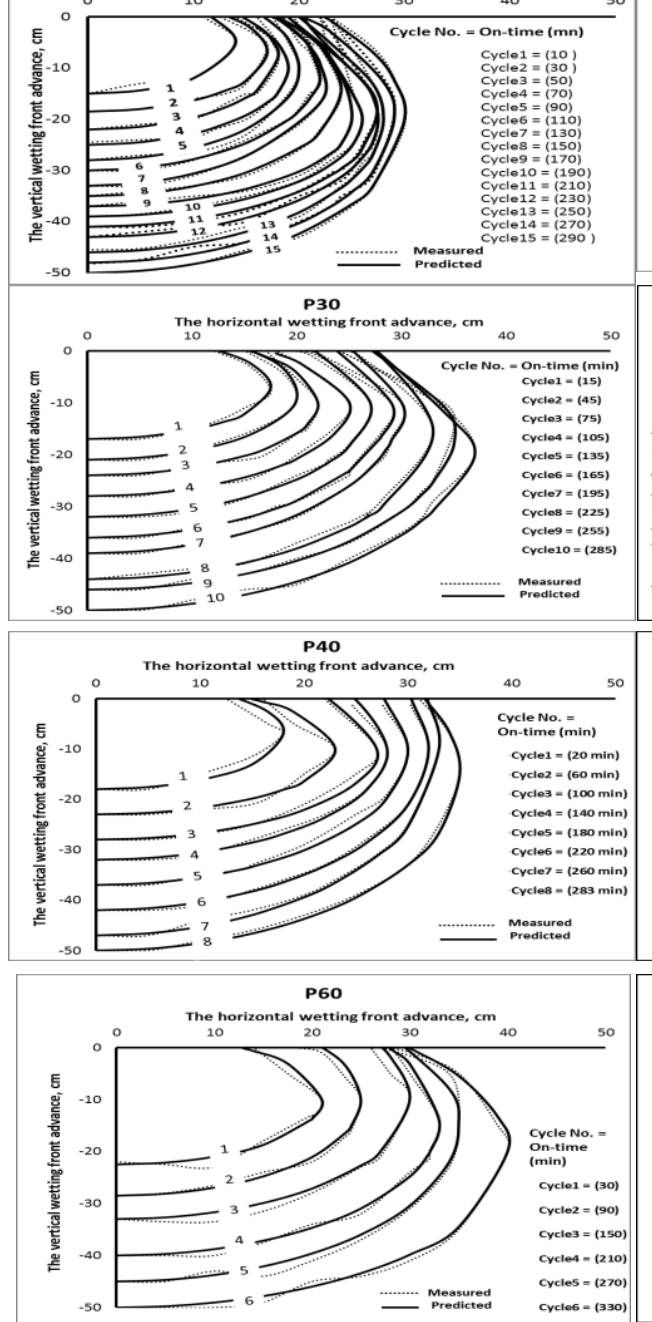

B
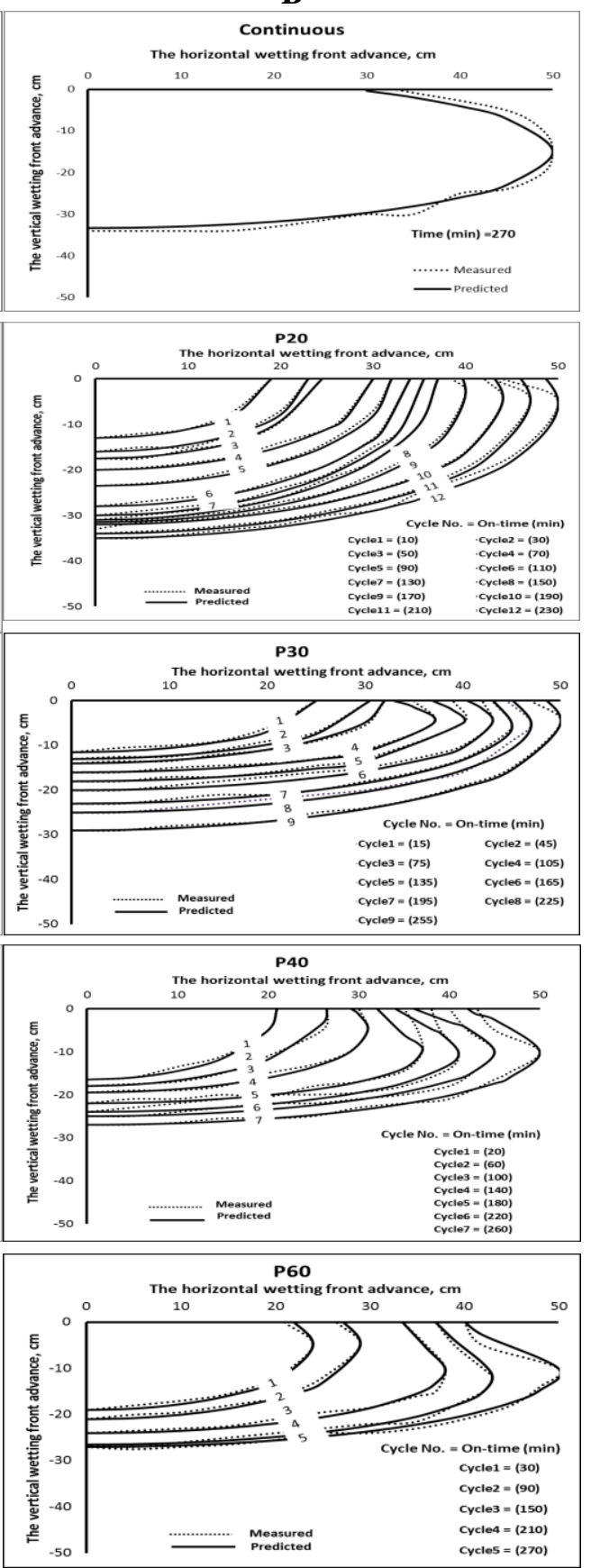

Fig. (8): The relationship between horizontal and vertical wetting front advance: a) without and. b) with using soil conditioner under continuous and pulsed drip irrigation. 
the percentage of increase in the soil surface wetted radius (Ri) for all treatments compared to continuous flow without soil conditioner polymer; Increase of the maximum wetted radius of dripper under soil surface (Rmax) more than wetted depth also, increase of percentage of the maximum wetted radius under soil surface to wetted depth under dripper (Rmax/D); and Increase of the horizontal wetting front advances more than the vertical wetting front advances; the surface and maximum wetted radius $\left(\mathrm{R}_{0}\right)$ takes total on-time $(270,120,135,140$ and $150 \mathrm{~min})$ for at treatments (C, P20, P30, P40, and P60), respectively.

Predicted and observed values were compared well to test model applicability in laboratory conditions on the basis of model performance parameters as root mean square, mean error and model efficiency. Thus, developed models can be used to predict wetting pattern under composite with pulsed flow method. The result shows the advantage of composite conditioner with pulsed flow method at cycle time 20 then, 30 minutes for reducing the deep percolation of water under the root zone, while obtaining a wide horizontal spread of wetting.

\section{REFERENCES}

Abdel tawab, E. (2015). Effect of Pulse and Continuous Drip Irrigation on Soil Wetting Pattern. Thesis of M.Sc., Alex. Univ., Egypt, 2015

Al-Darby, A.M. (1996): The hydraulic properties of a sandy soil treated with gel forming soil conditioner. Soil Technology, 9: 15- 28.

Ali, A. F. A. (2011). Study of Conditioning Effect of Hydrogels on Some Physical and Chemical Properties of Sandy Soil and Some Physiological Aspects in Cultivated Plants. A Thesis PhD, Bottany department, Facullty off Science, Sohag University.

Al-Ogaidi, A. A., Wayayok, A., Rowshon, M. K., and Abdullah, A. F. (2016). Wetting patterns estimation under drip irrigation systems using an enhanced empirical model. Agricultural Water Management, 176, 203-213.

Bakeer, G. A. A., El-Ebabi, F. G., El-Saidi, M. T., and Abdelghany, A. (2009). Effect of pulse drip irrigation on yield and water use 
efficiency of potato crop under organic agriculture in sandy soils. Misr J. Agric. Eng, 26, 736-765.

Dasberg, S., Or, D., 1999. Drip Irrigation. Springer-Verlag, Berlin, pp. 162.

El-Hady, O. A., Wanas, S. A., and Shaaban, S. M. (2006). Hydrophilic polymers for improving the conditioning effect of manures and organic composts. II. Hydrophysical properties of sandy soil planted with tomato. Egyptian Journal of Soil Science, 46(3), 283.

Eric, S., David, S. and Robert H. (2004). To pulse or not to pulse drip irrigation that is the question UF/IFAS - HORTICULTURAL SCIENCES DEPARTMENT. Florida,USA NFREC-SV-Vegetarian (04-05).

Ismail, S. M., EL-Abdeen, T. Z., Omara, A. A., and Abdel-Tawab, E. (2014). Modeling the soil wetting pattern under pulse and continuous drip irrigation. American-Eurasian Journal Agricultural \& Environment Science, 14(9), 913-922.

Li, J., Zhang, J., and Rao, M. (2004). Wetting patterns and nitrogen distributions as affected by fertigation strategies from a surface point source. Agricultural Water Management, 67(2), 89-104.

Maghchiche, A., Haouam, A., and Immirzi, B. (2010). Use of polymers and biopolymers for water retaining and soil stabilization in arid and semiarid regions. Journal of Taibah University for science, 4, 916.

Skaggs, T. H., Trout, T. J., and Rothfuss, Y. (2010). Drip irrigation water distribution patterns: effects of emitter rate, pulsing, and antecedent water. Soil Science Society of America Journal, 74(6), 1886-1896.

Subbaiah, R. (2013). A review of models for predicting soil water dynamics during trickle irrigation. Irrigation Science, 31(3), 225258.

Willmott, C. J., Robeson, S. M., and Matsuura, K. (2012). A refined index of model performance. International Journal of Climatology, 32(13), 2088-2094. 
Yang, L., Yang, Y., Chen, Z., Guo, C., and Li, S. (2014). Influence of super absorbent polymer on soil water retention, seed germination and plant survivals for rocky slopes eco-engineering. Ecological Engineering, 62, 27-32.

Zin El-Abedin, T. K., Mattar, M. A., and Alazba, A. A. (2015). Soil wetting pattern from subsurface drip irrigation as affected by application of a polyacrylamide layer. Irrigation and Drainage, 64(5), 609-618.

الملخص العربيى

تأثير محسنات التربة على أنماط ابتلال التربة تحت نظام الري بالتنقيط النبضي د. أحمد إبراهيم عبد الحكيمث*

من العوامل المهمة في تصميم و إدارة نظام الري بالتنقيط هو تقدير أنماط إبتلال النقاط تحت

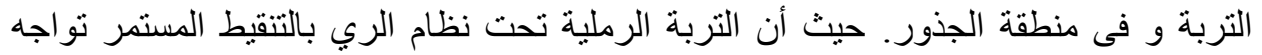

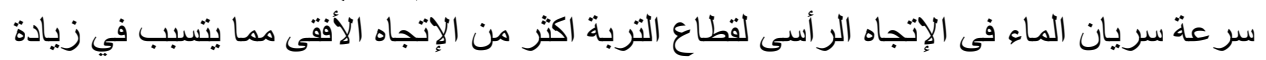

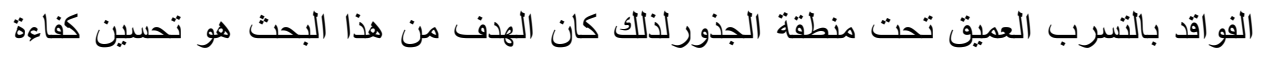

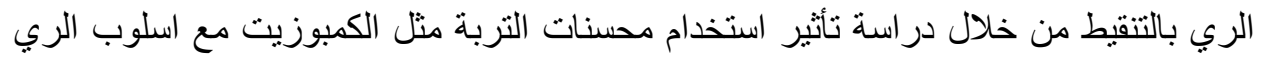

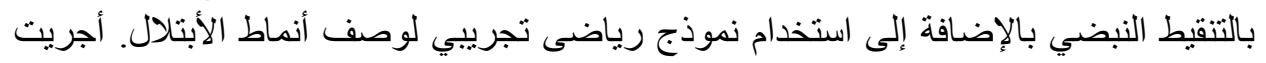

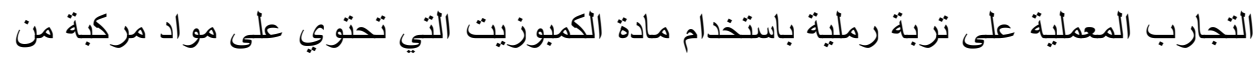

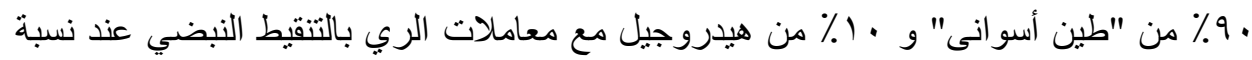

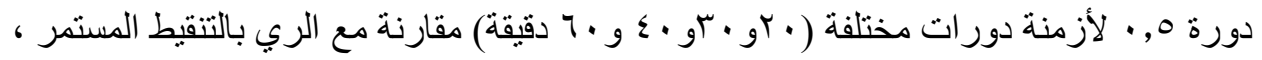

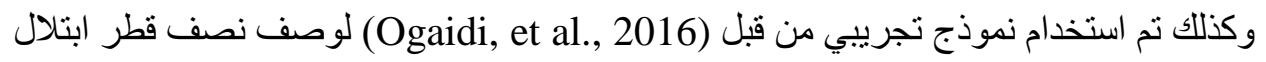

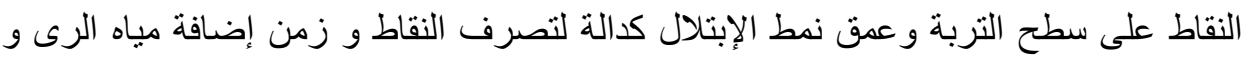

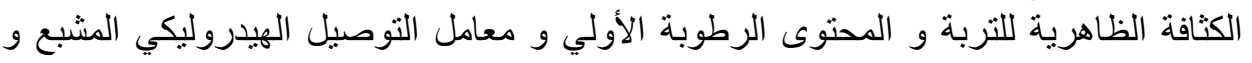

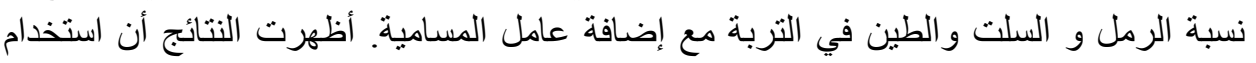

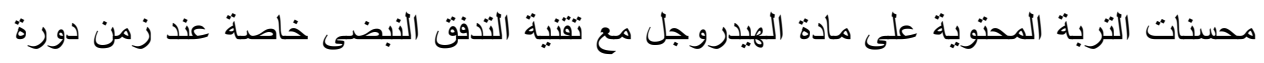

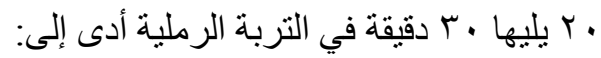

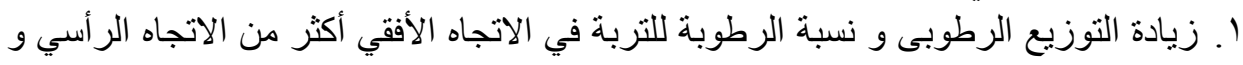

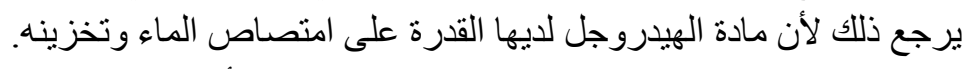

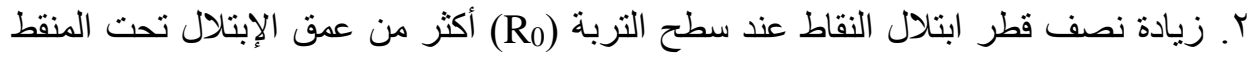

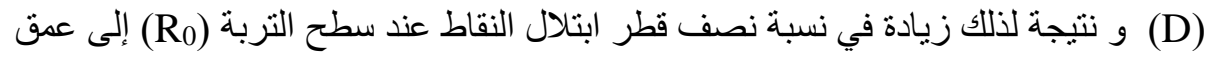

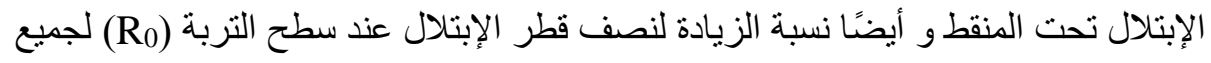

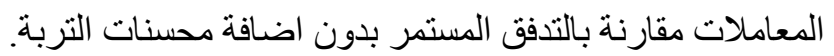

*باحث، معهد بحوث الهنسة الزراعية، مركز البحوث الزراعيةـ الجيزة 


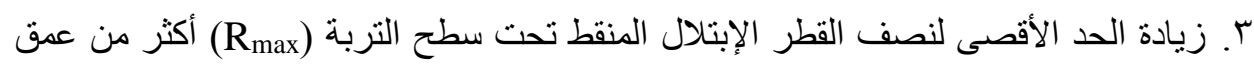

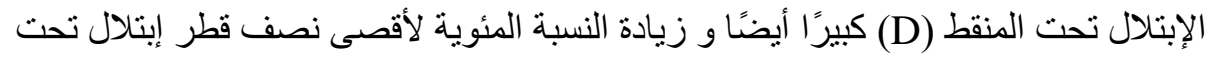

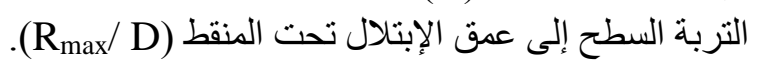

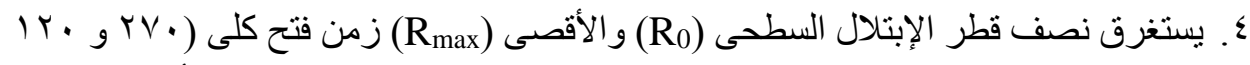

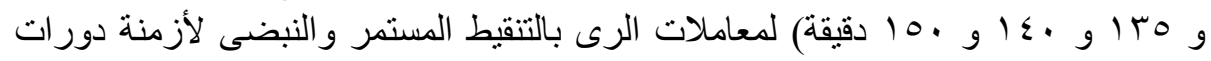

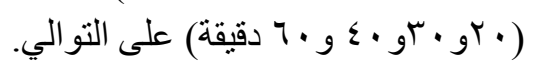

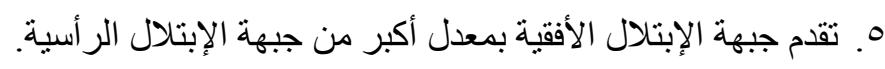

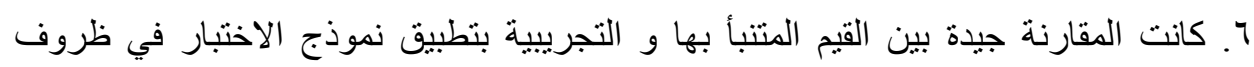

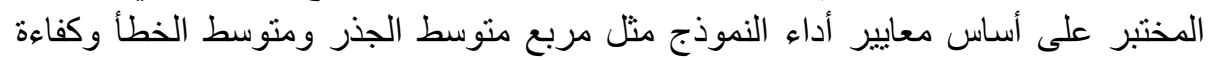

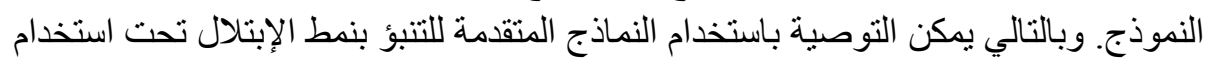

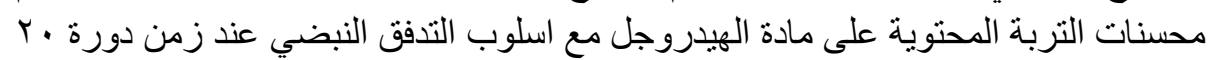

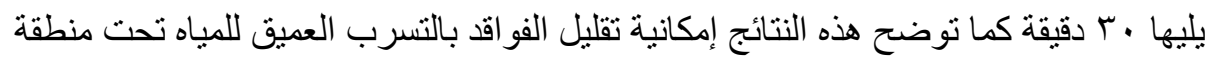
الجذور مع الحصول على انتشار أفقي واسع للإبتلال. 